\title{
LETTERS
}

\section{Simple-language tool to guide patients in recovery after prolonged treatment in the intensive care unit}

We were excited to read the article on 5 things to know about recovery after prolonged treatment in the intensive care unit, by Matteo Parotto and Margaret Herridge, published in CMAJ. ${ }^{1}$ These " 5 things" - communicated in simple language may help patients and families understand the recovery trajectory from prolonged intensive care unit (ICU) treatment and assist with goal setting. As health care providers who are dedicated to improving the care of patients with prolonged ICU treatment, we offer simple-language translations of these " 5 things," per the American Thoracic Society shared decisionmaking recommendations. ${ }^{2}$ We hope to continue the conversation about simple language, to help align expectations, goals and decision-making with our patients and their families.

Prolonged treatment in the ICU is when a patient has been in a critical care environment and has needed life support machines (such as a ventilator) for more than 1 week.

1. Patients who have prolonged ICU treatment may have new or worse physical, mental or emotional problems. These can last for at least a year after discharge from the ICU. This happens for at least 1 out of 4 patients.
2. Patients who have prolonged ICU treatment may have a nerve and muscle injury called "ICU-acquired weakness." This can result in tiredness, joint pain, poor mobility and needing help to take care of oneself (e.g., feeding, toileting). This happens for about half of patients.

3. Patients who have prolonged ICU treatment may have difficulty thinking, remembering things and making decisions. This can last for at least a year after discharge from the ICU. This happens for about 1 out of 3 patients.

4. Anxiety and depression occur in both patients and their family caregivers. This happens for at least 1 out of 3 patients and caregivers, and as many as 7 out of 10 patients and caregivers.

5. There may be a longer recovery time for patients, even if they had proper rehabilitation to help their physical, mental and emotional recovery.

There is a growing body of research on how to care for and treat people with prolonged ICU treatment and their families. ${ }^{3,4}$ Research on how to better manage pain, anxiety, communication problems and other ICU treatmentrelated symptoms may improve outcomes for patients with prolonged ICU stay, and decrease the proportion of people who live with long-lasting effects of prolonged ICU treatment.

\section{Laura Istanboulian MN-NP}

Nurse practitioner, Michael Garron

Hospital, Toronto, Ont.

\section{Lindsay Siple MHS}

Patient and family education specialist, Michael Garron Hospital, Toronto, Ont.

Cite as: CMAJ 2021 February 16;193:E251. doi: $10.1503 / \mathrm{cmaj} .77844$

\section{References}

1. Parotto M, Herridge MS. Recovery after prolonged treatment in the intensive care unit. CMAJ 2020;192:E1637.

2. Kon AA, Davidson JE, Morrison W, et al. Shared decision making in ICUs: an American College of Critical Care Medicine and American Thoracic Society policy statement. Crit Care Med 2016;44:188-201.

3. Dale CM, Carbone S, Istanboulian L, et al. Support needs and health-related quality of life of family caregivers of patients requiring prolonged mechanical ventilation and admission to a specialised weaning centre: a qualitative longitudinal interview study. Intensive Crit Care Nurs 2020;58:102808.

4. Rose L, Istanboulian L, Allum L, et al. Patient and family centered actionable processes of care and performance measures for persistent and chronic critical illness: a systematic review. Crit Care Explor 2019;1:e0005.

\section{Competing interests: None declared.}

Content licence: This is an Open Access article distributed in accordance with the terms of the Creative Commons Attribution (CC BY-NC-ND 4.0) licence, which permits use, distribution and reproduction in any medium, provided that the original publication is properly cited, the use is noncommercial (i.e., research or educational use), and no modifications or adaptations are made. See: https://creativecommons.org/ licenses/by-nc-nd/4.0/ 